\title{
Authorizing GM Crop Varieties: Policy Implications for Seed Systems in Sub-Saharan Africa
}

\author{
John Komen ${ }^{1, *(1)}$ and David K. Wafula ${ }^{2}$ \\ 1 Komen Bioscience Consultancy, 2023 WC Haarlem, The Netherlands \\ 2 East African Community, Afrika Mashariki Road, Arusha P.O. Box 1096, Tanzania; dwafula@eachq.org \\ * Correspondence: jce.komen@planet.nl
}

check for updates

Citation: Komen, J.; Wafula, D.K Authorizing GM Crop Varieties: Policy Implications for Seed Systems in Sub-Saharan Africa. Agronomy 2021, 11, 1855. https://doi.org/ 10.3390/agronomy11091855

Academic Editors: Niels P. Louwaars and Bram de Jonge

Received: 29 July 2021

Accepted: 13 September 2021

Published: 15 September 2021

Publisher's Note: MDPI stays neutral with regard to jurisdictional claims in published maps and institutional affiliations.

Copyright: (c) 2021 by the authors. Licensee MDPI, Basel, Switzerland. This article is an open access article distributed under the terms and conditions of the Creative Commons Attribution (CC BY) license (https:// creativecommons.org/licenses/by/ $4.0 /)$.

\begin{abstract}
Considering an expanding research and development pipeline of and growing practical experiences with genetically modified (GM) crops, governments in Sub-Sahara Africa have in recent years authorized various GM crop events for general, unconfined environmental release, and in a few cases, subsequent commercial variety registration and cultivation. These decisions are consistent with more business-oriented agricultural development policies aimed at turning agriculture into a leading driver of economic growth and wealth creation. Such policy reforms are also motivated by continent-wide initiatives described in this review paper, which emphasize seed sector reform, agricultural productivity growth, intra-regional trade, and agri-business development. While such policy developments spur a more proactive approach to introducing agricultural biotechnology, it becomes apparent that authorizing GM crops for general environmental release and commercial seed registration requires the harmonization of government policies in various sectors relevant to seed systems, most notably those affecting plant breeding research, testing, and variety release. Critical areas for such policy reforms and harmonization were analyzed in this paper, with associated recommendations.
\end{abstract}

Keywords: plant breeding; policy; seed regulation; genetic modification; gene editing; innovation pathways

\section{Introduction}

In December 2019, Nigeria's National Committee on Naming, Registration, and Release of Crop Varieties approved the registration of a genetically modified (GM) cowpea variety SAMPEA 20-T (unique identifier: AAT-7Ø9AA-4, full details recorded in the Biosafety Clearing-House, URL: https:/ / bch.cbd.int/database/record.shtml?documentid=114444, accessed 29 July 2021), which expresses resistance to the cowpea podborer, Maruca vitrata [1]. This landmark decision formed the culmination of two decades of biotechnology research and field testing through an international consortium led by the African Agricultural Technology Foundation. With this decision, Nigeria became the first country worldwide to authorize GM cowpea for cultivation by farmers, and the second country on the continent to authorize cultivation of GM food crops, in addition to South Africa, where GM maize was authorized for cultivation more than two decades ago.

The overall picture of GM crop adoption in sub-Sahara Africa is steadily evolving as a growing number of governments authorize their commercial adoption and have additional GM events in the R\&D pipeline. As of 2020, commercial cultivation involved seven countries, as shown in Figure 1 below, with another five countries planting GM crops in pre-commercial confined field trials [2]. While a detailed discussion of recent trends was beyond the scope of this review, notably, the majority of commercialization decisions has taken place in recent years (2019-2020). 


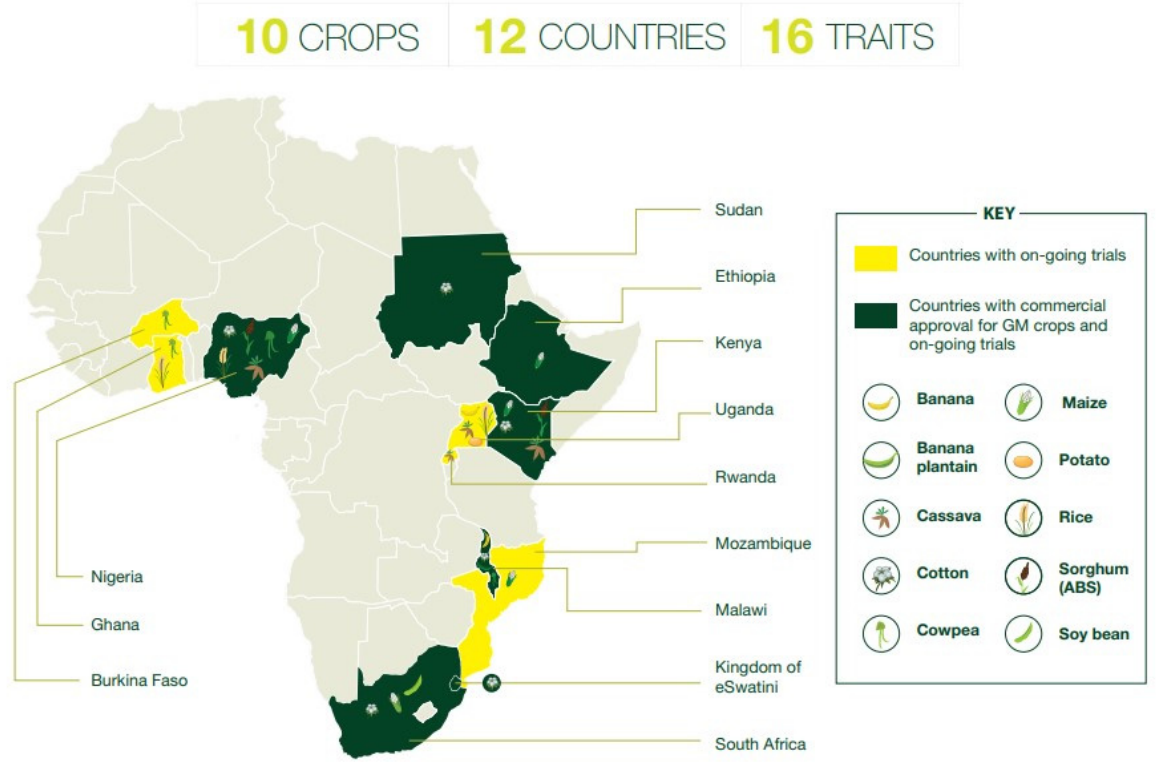

Figure 1. GM crop adoption in Sub-Saharan Africa, 2020. Source: ISAAA AfriCenter, 2021.

Before the podborer-resistant cowpea's variety registration was confirmed in Nigeria, a process of intensive government-agency collaboration and harmonization was set in motion in order to pave the innovation pathway for SAMPEA 20-T. Specific steps in this process will be described in more detail in this review paper. Evidently, while the variety registration represented a major regulatory decision, there is still a range of challenges, as described below, facing GM cowpea's (and other GM crops) actual adoption over time. Many of these are related to the fact that the introduction of GM varieties requires the implementation of specific policies and management practices by government agencies, local seed companies, and farmers that may not be commonplace in highly diverse agricultural production systems dominated by smallholders, where the use of commercial, certified seed is limited. However, if rationally designed, introduced, and implemented, such challenges may turn into opportunities for increased productivity of major food crops with associated economic and social benefits.

Focusing on seed sector impacts and management implications is now critical, considering the increasing adoption and dissemination of GM crops in Sub-Saharan Africa (SSA). This development is reflective of a shift in agricultural development policies across SSA toward increasing productivity and agri-business involvement. The introduction and adoption of GM crops increasingly feature in these policies, resulting in regulatory reforms to spur GM crop approvals. Such regulatory reforms have important reach-through implications on local seed sectors, which are already subject to rapid policy reforms, as described in this review paper.

\section{Seed Sector Reform in Sub-Saharan Africa}

Agricultural transformation, and in particular, food and nutrition security are at the heart of almost all African economies. A recent study by Baumüller et al. (2020) [3] looked in detail into the major current challenge facing African economies: How to transform its potentials into realities and actually secure its supply of food for affordable and healthy diets from the sustainable use of resources. As the authors state, "Africa's food imports amount to about US $\$ 60$ billion per year. In net terms, cereals account for about US $\$ 25$ billion per year, meat and dairy for US\$8 billion, the sugar sector for US\$4 billion and the vegetable oil sector for US\$9 billion. This market, which is primarily urban, holds great potential for African agriculture and food industries. So, the opportunities of capturing a growing market share by expanded African own food production are high." [3] (p. 8). Considering this challenge and related ones in terms of enhancing food security and nutrition in the face of climate change, 
in recent years, attention to agriculture by many governments, development partners, and the private sector has increased. Africa's agricultural sector growth has accelerated and in the past two decades, has been higher than in all other regions of the world [3] (p. 16). The authors propose a broad menu of investments and policy actions, acknowledging that "Good seeds for farmers remain a top investment and innovation priority." [3] (p. 10).

In the run-up to the United Nations' Food Systems Summit 2021, a major thematic focus involves the role of science, technology, and innovation (STI) for transforming food systems. Specifically for Africa, the potential of STI in improving production systems, human nutrition and health, and food processing is generally recognized. In a policy brief prepared for the 2021 Summit, Hendriks et al. [4] argued that "Change will need to be supported by institutional coordination; clear, food safety and health-conscious regulatory environments; greater access to information and transparent monitoring and accountability systems.". While agricultural production has increased, productivity increases through innovations lag behind compared to other regions. In light of rapid population growth, food system transformation must focus on productivity increases.

These general considerations are reflected in recent agricultural and STI strategies adopted by African countries, as summarized in the following sections, which will, among other things, affect the way seed systems are shaped and regulated.

\subsection{Agricultural Modernization Drive}

Recent successes in achieving rapid agricultural growth (e.g., in Ethiopia) have encouraged African governments to adopt much more growth- and agribusiness-orientated policies for agricultural development. At the continental level, the Comprehensive Africa Agriculture Development Program (CAADP), adopted in 2003, provides a guiding framework for catalyzing agricultural transformation at the continental, regional, and national levels. Through the CAADP agenda, African governments have agreed to increase public investment in agriculture to $10 \%$ of national budgets per year and to raise and maintain agricultural productivity and annual growth by at least $6 \%$. CAADP is designed to ensure a harmonized approach and convergence of efforts and strategies in addressing the challenges impacting on agriculture in Africa. The political impetus for driving and sustaining CAADP is embedded in the 2003 Maputo Declaration and the 2014 Malabo Declaration of African Union Heads of State and Government, which marked the 10th anniversary of CAADP. The program has been firmed up through a set of agreed upon commitments and indicators for measuring performance [5].

While progress toward meeting the targets is not satisfactory in virtually all signatory countries, seed is acknowledged as a critical input for agriculture and a key pathway to delivering agricultural innovations to farmers. The contribution of seed systems finds its relevance in a number of CAADP commitments. For instance, the commitment to ending hunger by 2025 has targets around doubling agricultural productivity through farm inputs (including seeds) and other interventions. Commitment to enhancing resilience in livelihoods and production systems is also one area where climate-smart, improved seed varieties would play a major role including those that are pest- and disease resistant or drought tolerant.

Implementation of the CAADP agenda is actualized through Regional Agriculture Investment Plans (RAIPs) and National Agriculture Investment Plans (NAIPs). Agricultural transformation strategies aligned to the NAIPs have been developed and launched by many countries in Africa. For instance, Kenya has its Agricultural Sector Transformation and Growth Strategy while Rwanda is implementing a Strategic Plan for Transformation of Agriculture in Rwanda.

\subsection{Continental and Regional Seed Policy Harmonization}

Reflecting the type of commitments laid down in CAADP and national government policies, over the last two decades, Regional Economic Communities in Africa have been engaged in the harmonization of seed policies, regulations, and legislation with the main 
goal of minimizing barriers to intra-regional trade in order to improve delivery of both the quantity and quality of seeds traded across borders. Priority areas of harmonization have included synchronization of national regulatory and coordination mechanisms, phytosanitary measures, common processes of seed certification, testing, release, and registration of plant varieties between member countries and establishment of common plant catalogues. It is anticipated that these efforts contribute to the development of a more formal seed sector supplying certified or quality-declared seeds. It should be noted that across Africa, the informal seed sector is still by far the main source of (uncertified) seeds. In the East African Community (EAC, Arusha, Tanzania), maize farmers lead the way in adopting certified seeds, estimated to be $20-30 \%$ of the total use [6].

At the sub-regional level, several policymaking bodies focus on seed policy harmonization. The Common Market for Eastern and Southern Africa (COMESA, Lusaka, Zambia) Harmonized Seed Regulations were adopted in 2014; the Economic Community of West African States (ECOWAS, Abuja, Nigeria) Seed Regulations passed in 2008; and, harmonized seed regulations for the Southern African Development Community (SADC, Gaborone, Botswana) were adopted in 2013. The EAC has a draft Seed and Plant Varieties Bill awaiting consideration by the Council of Ministers and the East African Legislative Assembly. Akinbo et al. (2021) presented a detailed description of such sub-regional harmonization efforts [7].

These regional instruments have no substantive provisions for the handling of GM seeds. For instance, the COMESA Seed Trade Regulations section on phytosanitary and seed documentation for import and export only requires National Seed Authorities to issue a declaration to certify the GM status of a seed consignment. As a separate policy, COMESA adopted a 'Biotechnology and Biosafety Policy' [8] in 2014, which addresses aspects of GM seeds for trade and commercial planting. Implementation of this policy has not materialized due to funding challenges. The objectives defined for COMESA's common policy are to [8] (p. 7):

1. Provide COMESA Member States with a mechanism for scientific regional risk assessment of GMOs intended for commercial planting, trade and food aid in the COMESA region;

2. Provide a technical opinion about the biosafety of GMOs seeking commercial status in the COMESA region that can be used by individual countries to make decisions within their own national biosafety regulatory frameworks;

3. Provide a harmonized mechanism for decision-making involving commercial planting, trade of GMOs, and food aid with GM content in the COMESA region;

4. Assist COMESA Member States share and build capacity in order to conduct scientific risk assessment and management; and

5. Establish interactive regional information sharing mechanism on biosafety and biotechnology issues in the COMESA region.

The draft EAC Seed and Plant Varieties Bill is silent on the handling of GM seeds. This implies that the handling of GM seeds has to be managed in accordance with evolving national biosafety policies and legislation.

Recently, under the leadership of the African Union (Addis Ababa, Ethiopia), there have been efforts to facilitate continental harmonization of seed systems. This is partly driven by the need to ensure alignment and harness benefits associated with the recently launched Africa Continental Free Trade Area (AfCFTA, Accra, Ghana). Development of continental guidelines under the African Union would inform and support the implementation of various Annexes of the AfCFTA that govern the functional and structural dimensions of the seed sector. This should subsequently inform continent-wide harmonization of seed legislation and standards. The African Union has also launched implementation of the Africa Seed and Biotechnology Program (ASBP). ASBP is based on the premise that Africa has not been able to take full advantage of the advances in seed sector development, mainly because of weak seed production and distribution systems, inadequate supply of quality seed, lack of access to improved germplasm, weak entrepreneurial capacity of small- 
and medium-size seed enterprises, and inadequate implementation of seed policies and international agreements and conventions [9]. The overall goal is to contribute to increased food security and nutrition and to poverty alleviation in Africa through the establishment of effective and efficient seed systems and enhanced application of biotechnologies and methodologies within the seed sector. Program objectives include: (i) increased capacity to utilize tools of biotechnology to enhance plant breeding and high-quality seed production; and (ii) increased capacity to implement biosafety measures in relation to seed production and distribution and plant genetic improvement to protect human health and the environment. In 2021, African Union initiated a process that will culminate in the development of non-binding continental guidelines for the use of biotechnology to enhance agricultural productivity for food security and nutrition security in Africa. The guidelines will provide guidance to Member States on how to safely harness biotechnology in their development agendas in tandem with the aspirations of AfCFTA.

\subsection{National Seed Policy Reforms}

While the above regional and continental initiatives may hold promise, the key policy challenge to introducing seed sector reforms is the fact that Africa's seed sector involves numerous players, sometimes with conflicting interests, operating in a loosely integrated value chain [10]. Seed systems in most SSA countries are still relatively underdeveloped, and many farmers plant open-pollinated varieties from previous harvests. Most farmers have yet to take the advantage of new crop varieties mainly due to weak seed production and distribution linkages, limited availability, lack of knowledge, cost, risk aversion, and preference for landrace varieties [10]. Against this background, a majority of African countries (with the exception of Mozambique, Cape Verde, Democratic Republic of the Congo, Djibouti, Guinea Bissau, and Mauritius) have introduced some form of seed policies, laws and regulations, or, govern the seed sector through ministerial orders or decrees. However, challenges of weak enforcement, inadequate resources, and poor coordination still prevail amongst institutions mandated with implementation and enforcement.

National policy reforms can be guided by the provisions and standards provided by international standard setting bodies. Currently, membership to such bodies as the International Union for the Protection of New Varieties of Plants (UPOV, Geneva, Switzerland), International Seed Testing Association (ISTA, Wallisellen, Switzerland), and the Organization for Economic Cooperation and Development (OECD, Paris, France) is varied across African countries. For instance, in the EAC, Kenya and Tanzania are members of UPOV, ISTA, and OECD seed schemes, while Uganda is a member of the OECD seed scheme only.

\section{Policy Implications of GM Crop Adoption}

\subsection{Implementing National Biosafety Frameworks}

The need for, progress to date, and challenges involved in defining and implementing functional regulatory systems governing the introduction of GM crops have been analyzed in a variety of publications and reports and will not be elaborated in this review paper. Generally, as with other new technologies, regulatory systems are one way for society to find a balance among the potential benefits, risks, and concerns emanating from genetic modification. Compliance with regulatory review procedures has by now become an essential element in the research, development, and product deployment strategies of public- and private-sector technology developers.

McLean, Foley, and Pehu (2012) analyzed the status and impact of biosafety regulation in developing economies [11], providing an overview of the key elements required for a functional national biosafety framework compliant with the Cartagena Protocol on Biosafety. The authors also point to the fact that: "Over the past decade, more than 140 developing countries or countries with transitional economies have received assistance to develop or implement national biosafety frameworks. Only a small number of developing countries have moved beyond these projects to operationalize their biosafety regulatory systems effectively, so 
that they may be considered functional — that is, they implement regulatory submission, assessment, and decision-making processes in a consistent, transparent, and predictable manner." Uneven progress in implementing national biosafety frameworks is also indicated in various reports of the Compliance Committee under the Cartagena Protocol on Biosafety, for example, in its most recent meeting report [12], which states that: "It also recognized, however, that limited progress had been reported in other areas, for example in relation to compliance with the obligation to take the necessary legal, administrative and other measures to implement the Protocol, and in relation to the obligation to submit a national report in a timely manner. The Committee discussed the need for Parties to have in place monitoring and enforcement systems for the implementation of the Protocol and that further efforts in that regard may be needed." [12] (p. 5).

Specifically for Sub-Saharan Africa, recent progress in building biosafety capacity and regulatory frameworks are presented by Wafula et al. (2012) [13], Komen et al. (2020) [14], and Akinbo et al. (2021) [7]. While also in this sub-region biosafety progress is uneven with many remaining challenges, several countries are making rapid progress [14], reflecting market-oriented agricultural policies as described in Section 2 above. Recent authorizations to cultivate GM crop varieties in Sub-Saharan Africa (excluding South Africa) involve:

- Insect-resistant, GM cotton hybrids, marketed by Indian seed firms JK Seeds and Mahyco, are approved for cultivation in Ethiopia, Eswatini, Kenya, Malawi, Nigeria and Sudan;

- Insect-resistant cowpea, as above-mentioned, was approved for cultivation in Nigeria in 2019, while official seed sales started in June 2021;

- Additional GM food crops are advancing through the regulatory pipeline; for example, Kenya's National Biosafety Authority approved virus-resistant cassava in June 2021 to proceed with national performance trials [15].

Such authorizations do not constitute an end point in the innovation and regulatory process as they have important implications for seed development, delivery, and distribution, requiring policy reforms that affect the local seed systems. Additionally, as part of the process toward authorizing cultivation of GM crop varieties, critical steps must be made in harmonizing different government-agency mandates affecting the commercial release of GM crops. These policy implications and associated policy reforms are described in Sections 3.2 and 3.3 below.

\subsection{Harmonizing Government Pre-Market Regulatory Mandates}

Obviously, important progress has been achieved in several countries in Sub-Saharan Africa despite a myriad of challenges. Among these, biosafety regulatory reviews and decisions are often hampered by a lack of coordination among government agencies and sometimes conflicting legal mandates. Such mandate issues will have to be addressed prior to the issuing of general release permits in order to avoid legal challenges. Examples related to harmonization challenges in authorizing GMO general environmental releases include the following.

\subsubsection{Biosafety Risk Assessment vs. Environmental Impact Assessment}

In many jurisdictions, biosafety legislation is developed and implemented separately from general environmental protection legislation and housed in different ministries. This situation calls for intra-government harmonization efforts; if not effectively addressed, it would lead to protracted regulatory delays. A case in point is Kenya, where the National Biosafety Authority (NBA) was established by an act of Parliament in 2009. While the NBA should act as a one-stop shop for all matters related to GMO regulation, this role has been difficult to fulfil due to mandate overlap with the National Environment Management Authority (NEMA). Prior to authorizing a general environmental release, NBA conducts an Environmental Risk Assessment (ERA), which is submitted for decision-making by the NBA Board of Directors. During the process, NBA consults with relevant regulatory agencies including NEMA, which until recently also had a seat on the NBA Board. In principle, under the National Biosafety Act (2009), the NBA has the mandate to authorize general 
environmental releases of GMOs and placing on the market. However, a 2017 amendment to NEMA's Environmental Impact Assessment (EIA) regulations included the requirement to conduct EIA for all projects involving "Major developments in biotechnology including the introduction and testing of genetically modified organisms." [16]. While this part of the amendment is questionable from a strictly legal point of view, in practice, this has resulted in a situation where, to date, NBA only issues "conditional approvals" for environmental releases of GM crops for the purpose of conducting National Performance Trials (NPTs) and with the condition that an EIA license is secured from NEMA. Authorizations for cultivation and placing on the market would then be issued in subsequent stages.

Obviously, these additional steps and review rounds lead to prolonged delays in the innovation process. For example, NBA authorized NPTs for insect resistant, Bt maize in 2017, but these trials only began in 2020 following over three years of uncertainty over the issuing of an EIA license for the six proposed NPT sites [17]. In addition, confusion over legal mandates creates opportunities for political interference: the EIA license initially provided by NEMA in 2017 was subsequently retracted citing the GMO import ban imposed by Kenya's Cabinet in 2012 [17]. While this ban would only affect GMO importations for direct consumption as food, this way, it still constrains the innovation pathway for improved maize in Kenya.

\subsubsection{Food and Feed Safety Assessment}

A similar situation of internally asynchronous review processes may occur for GM food and feed safety assessments. In many countries, authority for food approvals including those derived from GMOs, lies outside the mandate of national biosafety agencies, for instance, with a public health ministry or autonomous food safety authority. In addition, authority for animal feed authorizations often rests with agricultural ministries or a specialized agency. General food and feed safety legislation and guidelines often pre-date the adoption of a biosafety regulatory framework. This situation calls for close coordination between food safety and biosafety authorities and clarifying which is the competent authority for GM food and feed. Ideally, authorization processes for general environmental release and food/feed safety take place concurrently to avoid unnecessary delays.

Effective coordination occurs in Nigeria, where relevant agencies such as the National Agency for Food and Drug Administration and Control (NAFDAC) and Federal Ministry of Agriculture are represented in the National Biosafety Committee that provides scientific advice to the National Biosafety Management Agency (NBMA). Their assessments contributed to simultaneous approvals (general release, food, and feed) for GM podborerresistant cowpea. As an agency under the Federal Ministry of Environment, NBMA is fully authorized to issue permits for different types of GMO applications (such as field trials, commodity exports, general releases), independent from endorsement by higher levels of government. NBMA has developed and signed Memorandums of Understanding with a range of regulatory agencies including NAFDAC to streamline review processes and to avoid confusion over each agency's legal mandate.

Absence of such a coordinated approach leads to lengthy decision-making processes: For example, Indonesia authorized drought-tolerant sugarcane for cultivation (by the biosafety competent authority) and for food uses (by the national food safety agency) in 2013 [18]. However, as guidelines for assessing feed safety-part of the mandate of the Ministry of Agriculture-were lacking at that time, final approval was issued only five years later, in August 2018 [19].

\subsubsection{Biosafety Field Trials and National Variety Testing Schemes}

A third area of regulatory harmonization concerns the mandates of biosafety authorities and variety release authorities. While a few countries have established detailed protocols for conducting GM biosafety field trials, African biosafety authorities generally require multiple seasons of small-scale, confined field trials (CFTs) for GM crops, followed by multi-location trials in different agroecological zones, prior to approving general envi- 
ronmental release for performance trials and subsequent cultivation. In such trials, the GM crop is compared to its non-GM counterpart for a phenotypic comparison and for analysis and comparison of crop composition. This phase is a cornerstone to pre-release safety assessment. Subsequent performance trials for variety registration focus on phenotypic characteristics, not safety aspects, to determine DUS (Distinctness-Uniformity-Stability) and VCU (Value for Cultivation and Use).

The interface between biosafety regulatory systems and variety release systems, with reference to Sub-Saharan Africa, is described in detail by Akinbo et al. (2021) [7]. The authors point to the fact that the transition from a biosafety regulatory review, for environmental and food/feed safety, to variety testing and release programs is not automatic or smooth, and that important gains can be made if the various authorities were aligned more closely. Based on a set of country case studies from Sub-Saharan Africa, they recommend that National Performance Trial Committees develop guidelines for conducting national performance trials (NPTs) of approved GM events, covering DUS and VCU aspects, and not be concerned with food, feed, and environmental safety data as these aspects are covered by biosafety competent authorities [7] (p. 15). Confusion over the scope of NPTs for GM events had indeed resulted in regulatory delays in case-study countries.

In fact, a case can be made to better integrate biosafety field trials with NPTs for variety registration, thereby shortening the time required for various field-testing cycles. A comprehensive analysis of biosafety field trial protocols and their possible integration into field trial schemes for variety registration by Slot et al. [20] concludes that "The fact that both types of field trials are part of pre-market assessment procedures and that the requirements are highly similar, seems to argue for more efficient procedures. Sharing the data for both pre-market assessment procedures would help to perform the field trials as cost-efficient as feasible." (p. 328). Applying this recommendation would lead to considerable time savings for GM variety releases in Sub-Saharan Africa, where multiple seasons of variety testing and on-farm demonstration trials are usually added to the biosafety and food/feed safety assessment cycles.

A first step in harmonizing requirements for biosafety CFTs and NPTs was made in Kenya, where the Kenya Plant Health Inspectorate Service spearheaded the development of "Guidelines for Conducting National Performance Trials and Distinctness, Uniformity and Stability Tests on Genetically Modified Crops in Kenya" [21]. These guidelines confirm Kenya's NBA authority over GMO biosafety releases and focus on agronomic performance testing while not repeating biosafety field trials. The following principles are laid down in the guidelines to align biosafety trials and NPTs [21]:

i. Where the unmodified version of the GM variety has been previously released in the same crop variety for the same agroecological site or purpose, the GM variety will be considered an essentially derived variety. Use of NPT results of the unmodified version of an EDV may be requested by the applicant.

ii. Subject to approval by the National Performance Trials Committee, testing may be done for only one season to confirm the expression of the introduced trait, so long as testing is conducted in more than three sites.

iii. Where the unmodified version of the GM variety has not been previously released, the GM variety will be considered to be a new variety even if the modified trait has been used in other varieties.

\subsection{Ensuring Product Release and Stewardship}

Once a GM crop has completed the full review cycle for environmental safety, food and feed safety, and DUS/VCU testing, further steps are required to ensure its launch as a new variety for cultivation and safeguarding its sustainability. Again, policy considerations and necessary policy reforms are involved in these final stages, which are analyzed in the sections below. 


\subsubsection{Provisions in General Seed Laws}

Prior to the planting of GM crop varieties in farmers' fields, either from domestically produced or imported seeds, they will have to be authorized as certified seed or quality-declared seed in most SSA countries. For most crops, this condition is commonly regulated under general seed laws and regulations. Generally there are no fundamental obstacles to certifying GM seeds under these legal frameworks; however, the absence of specific procedures for authorizing GM seeds often leads to a level of indecision with seed certification bodies as their legal mandates often pre-date the adoption of biosafety regulatory regimes and may not be fully aligned with biosafety competent authorities.

Therefore, an explicit reference to biosafety legislation, when in force, and the relevant biosafety competent authority would serve to clarify seed regulation involving GM plants and a smooth transition from the biosafety regulatory realm. In Uganda, for example, the Seed and Plant Act of 2007 [22] states that "Genetically modified seeds will be regulated in accordance with the Uganda National Council of Science and Technology Act or any relevant law." In Nigeria, the National Agricultural Seeds Council Act (2019) asserts that "Genetically modified varieties are considered if they conform to the bio-safety regulations of Nigeria [ ... ]" [23].

\subsubsection{Dealing with Low Level Presence}

Related to the points summarized in Section 3.3.1 above is the specific question of dealing with low level presence. Generally, low level presence, sometimes used interchangeably with 'adventitious presence', is defined as the unintended incidence of something other than the desired crop. This could include small quantities of weed seeds, seeds from other crops, dirt, insects, or foreign material (e.g., plastic or stone). Specific to GM crops, the UN Food and Agriculture Organization uses the following working definitions: (i) Low Level Presence (LLP): The detection of low levels of GM crops that have been approved in at least one country; (ii) Adventitious Presence (AP): Detection of the unintentional presence of GM crops that have not been approved in any countries. For the purpose of this review the term low level presence (LLP) is used. The LLP of GM seeds in seed supplies is marketed as conventional or organic. With the expected increasing adoption of, and trade involving GM crops in SSA, LLP of GM seeds will grow along with a corresponding increase in the difficulty of obtaining seed purity thresholds and LLP allowances as currently defined in national seed laws and regulations. LLP can be minimized using good agricultural practices and identity preservation schemes; however, it cannot be eliminated entirely and is not unique to GM crops. While practical measures and thresholds can be defined following current seed sector regulations, these may not be acceptable to (potential) international trading partners who sometimes apply a zero-tolerance policy toward unauthorized GM crops or to local organic farming groups.

Obviously, this is a recently emerging topic for seed sector authorities in SSA and examples or best practices from the region are scarce. Practical guidelines and criteria will have to be adopted in countries where GM seeds are planted commercially, in line with existing guidance on seed purity. International guidance, for example, from the International Seed Testing Association will be valuable to the SSA seed sector. A critical element in the enforcement of any LLP guidance will be the capacity-in terms of human skills development and development of common methodologies- to inspect and detect GM seed presence. Initial capacity development in this area is supported by RAEINAfrica (RAEIN-Africa: Regional Agricultural and Environmental INnovations-Africa. URL: https:/ / www.raein-africa.org/about-us/; accessed 29 July 2021), who implements a "Multi-Country Project to Strengthen Institutional Capacities on LMO Testing in Support of National Decision Making" supported through the United Nations Environment Program and involving six SSA countries.

\subsubsection{Stewardship Requirements and Insect Resistance Management}

In order to maintain long-term value to farmers from GM technology and to facilitate compliance with biosafety regulations and permit conditions, public and private technology 
developers have introduced detailed stewardship requirements for commercialized GM varieties, covering each stage of the entire life cycle from its inception in research, through product development and commercialization to product phase out. This is similar to the way the international agro-industry developed and implemented stewardship programs for crop protection products. Specific aspects for GM crops relate to the need for Insect Resistance Management (IRM) - preventing the build-up of pests and pest resistance to insect-resistant GM crops-and weed-resistance management as applied to herbicidetolerant GM crops. In countries that have extensively adopted GM varieties, the seeds usually come with detailed 'technology use guides' including detailed instructions to farmers on general best management practices and IRM requirements as applicable.

For SSA countries, reaching out to farmers with technology use guides and growers' agreements for technology stewardship may not be a realistic option in highly diverse, smallholder dominated farming systems. Besides, local seed purity regulations may not allow for the blending of seeds for IRM purposes. Consequently, new ways of ensuring technology stewardship are defined, for example, to manage the introduction of GM cowpea in Nigeria. For this specific case, a detailed approach to farmer extension was presented by Khalid et al. [24]. According to the authors, a public-private partnership was forged involving the technology developers-the African Agricultural Technology Foundation and Nigeria's Institute for Agricultural Research-the National Agricultural Seed Council and the National Agricultural Extension Research and Liaison Services. In collaboration with local seed companies, a quality management system was set up to ensure proper documentation, seed testing, packaging, and labelling. The same partnership defined an appropriate IRM strategy to ensure long-term pest control [24]. The IRM plan is based on the high-dose/refuge strategy where non-GM cowpea, cowpea landraces, and natural refuges are expected to keep the insect pest (Maruca vitrata) susceptible to the toxins expressed by SAMPEA T-20 [25]. The IRM plan will require intensive outreach to cowpea farmers, which in fact was among the objectives of on-farm demonstration trials conducted during 2020 [26].

Any product stewardship management scheme would be undermined by the diffusion of counterfeit and adulterated seed, which is generally afflicting the SSA seed sector. With the introduction of improved GM crops, it is expected that counterfeit and adulterated seeds will become a major threat that can destroy the farmers' confidence in the product and recommended management practices. Experience in the Philippines with GM maize showed that, over time, counterfeit seed tended to take up an increasing proportion of the total area planted [27] and, as they were not distributed with the IRM refuge, critically affect the technology's sustainability. For GM cowpea in Nigeria, methods of detecting counterfeit seed are being tested, primarily through the mobile authentication service method, launched originally by NAFDAC to detect fake anti-malarial drugs and antibiotics [24]. This method used scratch verification codes and short messaging service to enable buyers to verify the authenticity of the medicine at the point of purchase. Farmers in Nigeria and in other SSA countries are increasingly practicing certified seed verification using cell phones. Such methods are not unique to Nigeria and have been successfully applied in, for example, India.

\section{Discussion: Harmonization Efforts and Practical Steps}

It is generally recognized that good quality seed is fundamental to enhancing agricultural productivity, increasing food security, and improving rural livelihoods. Ensuring its availability and access will be a continuing challenge in SSA, considering the steady rise in the number of undernourished people [28]. The legal and regulatory environment at the national and sub-regional levels is a significant factor impacting the availability and accessibility of improved seed. As the seed sector in SSA continues to evolve, new dimensions and layers of regulation are added that increase complexity. These are associated with the current drive toward more private sector driven agricultural development 
including the application and adoption of GM crop varieties. The broad implications of these developments are that:

- Plant breeding, from contained use experiments to field testing, becomes subject to, and needs to consider early-on in the R\&D process, various environmental regulations, particularly those related to biosafety and EIA, and regulations covering food and feed safety.

- Processes for variety registration need to be aligned with biosafety procedures and, where relevant, EIA requirements. Performance data generated during biosafety field testing could be incorporated into testing schemes to determine DUS/VCU.

- When a new GM variety is launched as commercial seed for farmers, various factors need to be considered such as (i) general stewardship practices; (ii) pest resistance management, as relevant; (iii) stipulations in seed laws and regulations that affect the blending of seeds for refugia purposes; and, (iv) dealing with adventitious presence in conventional seed sales.

While agricultural research and product development is already a tightly regulated sector in most countries, the above challenges may seem daunting to research leaders, regulators, and policymakers in SSA. However, examples are presented above that provide practical ways of addressing identified challenges, which could be adopted in countries with limited experience to date in GMO management. Institutional innovations such as close intra-government coordination through MoU's and representation in national biosafety committees are emerging that expedite timely reviews and decision-making. In addition, public-private partnerships to guide the proper introduction of GM technology at commercial scale, as adopted in Kenya and Nigeria, can be effective mechanisms to ensure familiarity, farmer awareness, and product stewardship. Finally, policy reforms that underpin harmonization of regulatory mandates such as between procedures for biosafety testing and DUS/VCU testing can be adopted in multiple countries. Together, these are practical ways in which policy and regulatory challenges can be addressed that may benefit agricultural innovation in the long run.

As sub-regional policy bodies such as COMESA and, at the continental level, the African Union are defining their guidance toward biotechnology and biosafety; ideally, such issues are addressed regionally and, possibly result in harmonized policy approaches among SSA countries and their trading partners.

\section{Conclusions}

As seed system policies and regulatory frameworks in SSA are evolving and the overall pattern is becoming even more diverse as a result of the introduction of GM seeds in several countries, government agencies have to prepare for the judicious introduction and dissemination of these new technologies. Coordinated approaches among government agencies are critical, as described in this review. At the continental level, while guidance from Africa-based RECs is still limited, these organizations are uniquely placed to share emerging best practices for the benefit of countries that presently have limited capacity and expertise, and, in the longer run, encourage the formulation and adoption of common guidelines to manage the introduction and intra-regional trade involving GM seeds.

Author Contributions: All authors listed have made substantial, direct, and intellectual contribution to the work and approved it for publication. All authors have read and agreed to the published version of the manuscript.

Funding: This research received no external funding.

Conflicts of Interest: The authors declare no conflict of interest.

\section{References}

1. Okojie, J. Nigeria Commercialises First Transgenic Cowpea Variety. Business Day, 17 December 2019. Available online: https: / / businessday.ng/agriculture/article/nigeria-commercialises-first-transgenic-cowpea-variety/(accessed on 13 September 2021).

2. ISAAA AfriCenter. Towards the Crowning Moment: ISAAA AfriCenter 2020 Annual Report; ISAAA AfriCenter: Nairobi, Kenya, 2021. 
3. Baumüller, H.; von Braun, J.; Admassie, A.; Badiane, O.; Baraké, E.; Börner, J.; Bozic, I.; Chichaibelu, B.; Collins, J.; Daum, T.; et al. From Potentials to Reality: Transforming Africa's Food Production (Investment and Policy Priorities for Sufficient, Nutritious and Sustainable Food Supplies); Center for Development Research: Bonn, Germany, 2020.

4. Hendriks, S.L.; Bekele, E.; Chaibi, T.; Hassan, M.; Miano, D.W.; Muyonga, J.H. The Role of Science, Technology, and Innovation for Transforming Food Systems in Africa. In Food Systems Summit Brief Prepared by Research Partners of the Scientific Group for the Food Systems Summit; Network of African Science Academies: Nairobi, Kenya, 2021.

5. CAADP. The CAADP Results Framework 2015-2025. "Going for Results and Impacts"; NEPAD Planning and Coordinating Agency: Pretoria, South Africa, 2015.

6. Westengen, O.T.; Haug, R.; Guthiga, P.; Macharia, E. Governing Seeds in East Africa in the Face of Climate Change: Assessing Political and Social Outcomes. Front. Sustain. Food Syst. 2019, 3, 53. [CrossRef]

7. Akinbo, O.; Obukosia, S.; Ouedraogo, J.; Sinebo, W.; Savadogo, M.; Timpo, S.; Mbabazi, R.; Maredia, K.; Makinde, D.; Ambali, A. Commercial Release of Genetically Modified Crops in Africa: Interface Between Biosafety Regulatory Systems and Varietal Release Systems. Front. Plant Sci. 2021, 12, 314. [CrossRef] [PubMed]

8. Waithaka, M.; Belay, G.; Kyotalimye, M.; Karembu, M. Progress and Challenges for Implementation of the Common Market for Eastern and Southern Africa Policy on Biotechnology and Biosafety. Front. Bioeng. Biotechnol. 2015, 3, 109. [CrossRef] [PubMed]

9. African Union. African Seed and Biotechnology Programme; African Union: Addis Ababa, Ethiopia, 2020.

10. Ariga, J.; Mabaya, E.; Waithaka, M.; Wanzala-Mlobela, M. Can improved agricultural technologies spur a green revolution in Africa? A multicountry analysis of seed and fertilizer delivery systems. Agric. Econ. 2019, 50, 63-74. [CrossRef] [PubMed]

11. McLean, M.; Foley, M.; Pehu, E. The Status and Impact of Biosafety Regulation in Developing Economies Since Ratification of the Cartagena Protocol; Joint Departmental Discussion Paper No. 3; World Bank: Washington, DC, USA, 2012.

12. Compliance Committee under the Cartagena Protocol on Biosafety. Report of the Compliance Committee under the Cartagena Protocol on Biosafety on the Work of its Seventeenth Meeting; CBD/CP/CC/17/6; Convention on Biological Diversity: Montreal, QC, Canada, 2020.

13. Wafula, D.; Waithaka, M.; Komen, J.; Karembu, M. Biosafety legislation and biotechnology development gains momentum in Africa. GM Crop. Food 2012, 3, 72-77. [CrossRef] [PubMed]

14. Komen, J.; Tripathi, L.; Mkoko, B.; Ofosu, D.O.; Oloka, H.; Wangari, D. Biosafety Regulatory Reviews and Leeway to Operate: Case Studies from Sub-Sahara Africa. Front. Plant Sci. 2020, 11, 130. [CrossRef] [PubMed]

15. NBA. NBA Board Approves Environmental Release Application for GM Cassava. Press Release, 22 June 2021. Available online: https:/ / www.biosafetykenya.go.ke/images/NBA-Board-Approves-application-for-Genetically-Modified-Cassava-FINAL pdf (accessed on 22 June 2021).

16. NEMA. Environment Impact Assessment (EIA). Available online: https://www.nema.go.ke/index.php?option=com_content\& view $=$ article\&id=119\&Itemid $=144$ (accessed on 21 June 2021).

17. Ngotho, A. Breeders Urge NEMA to Issue Permit for GMO Performance Trials: EIA Certificate Given by NEMA Retracted Citing Implications of the GMO Ban Imposed in 2012. The Star, 25 September 2019.

18. ISAAA GM Approval Database. Available online: https://www.isaaa.org/gmapprovaldatabase/event/default.asp (accessed on 21 June 2021).

19. USDA Foreign Agricultural Service. Indonesia Agricultural Biotechnology Annual 2018; GAIN Report No. ID1838; US Department of Agriculture, Foreign Agricultural Service: Washington, DC, USA, 2018.

20. Slot, M.M.; Van De Wiel, C.C.M.; Kleter, G.A.; Visser, R.G.F.; Kok, E.J. The assessment of field trials in GMO research around the world and their possible integration in field trials for variety registration. Transgenic Res. 2018, 27, 321-329. [CrossRef] [PubMed]

21. KEPHIS. Guidelines for Conducting National Performance Trials and Distinctness, Uniformity and Stability Tests on Genetically Modified Crops in Kenya; Kenya Plant Health Inspectorate Service: Nairobi, Kenya, 2018.

22. Government of Uganda. The Seeds and Plants Act, 2006; The Uganda Gazette: Uganda, South Africa, 2007 ; Volume C, p. 132.

23. Federal Republic of Nigeria. National Agricultural Seeds Council Act; Federal Republic of Nigeria Official Gazette: Nigeria, South Africa, 2019; Volume 106, pp. A1-A31.

24. Khalid, I.O.; Onyekachi, F.; Mbabazi, R.; Maredia, K. Agricultural Extension Services \& Seed Systems for Agricultural Tech-nology Transfer in Nigera. In Innovations in Agricultural Extension; National Institute of Agricultural Extension Management, and Michigan State University Extension: East Lansing, MI, USA, 2021.

25. Addae, P.C.; Ishiyaku, M.F.; Tignegre, J.-B.; Ba, M.N.; Bationo, J.B.; Atokple, I.D.K.; Abudulai, M.; Dabiré-Binso, C.L.; Traore, F.; Saba, M.; et al. Efficacy of a cry1Ab Gene for Control of Maruca vitrata (Lepidoptera: Crambidae) in Cowpea (Fabales: Fabaceae). J. Econ. Ėntomol. 2020, 113, 974-979. [CrossRef] [PubMed]

26. Agbo, J. IAR, AATF Kickstart Nationwide On-Farm Demonstrations of PBR Cowpea. The Nation, 26 August 2020. Available online: https://thenationonlineng.net/iar-aatf-kickstart-nationwide-on-farm-demonstrations-of-pbr-cowpea/(accessed on 21 June 2021).

27. Icamina, P. “Fake GM Corn” Eating into Filipino Farmers' Profits. SciDevNet, 2 July 2018. Available online: https://www.scidev. net/asia-pacific/news/fake-gm-corn-eating-into-filipino-farmers-profits/(accessed on 21 June 2021).

28. FAO. 2019 Africa Regional Overview of Food Security and Nutrition; FAO: Accra, Ghana, 2020. [CrossRef] 